\title{
Late Cardiovascular Morbidity and Mortality Following Pediatric Allogeneic Hematopoietic Cell Transplantation
}

\author{
Christine N. Duncan ${ }^{1}$, Ruta Brazauskas ${ }^{2,3}$, Jiaxing Huang ${ }^{3}$, Bronwen E. Shaw ${ }^{3}$, Navneet S. \\ Majhail $^{4}$, Bipin N. Savani ${ }^{5}$, Mary E.D. Flowers ${ }^{6}$, Minoo Battiwalla ${ }^{7}$, Kristen Beebe ${ }^{8}$, Andrew \\ C. Dietz ${ }^{9}$, Christopher C. Dvorak ${ }^{10}$, Roger Giller ${ }^{11}$, David A. Jacobsohn ${ }^{12}$, Morris Kletzel ${ }^{13}$, \\ Paul L. Martin ${ }^{14}$, Eneida R. Nemecek ${ }^{15}$, Brandon Nuechterlein ${ }^{11}$, Julie-An Talano ${ }^{16}$, Michael \\ A. Pulsipher ${ }^{9,}$, , and K. Scott Baker ${ }^{6,}{ }^{*}$
}

1'Dana-Farber/Boston Children's Cancer and Blood Disorders Center, Boston, Massachusetts ${ }^{2}$ Center of International Blood and Marrow Transplant Research, Froedtert and the Medical College of Wisconsin, Milwaukee, Wisconsin ${ }^{3}$ Division of Biostatistics, Institute for Health and Society, Medical College of Wisconsin, Milwaukee, Wisconsin ${ }^{4}$ Department of Hematology and Oncology, Cleveland Clinic Taussig Cancer Institute, Cleveland, Ohio ${ }^{5}$ Division of Hematology/ Oncology, Department of Medicine, Vanderbilt University Medical Center, Nashville, Tennessee ${ }^{6}$ Clinical Research Division, Fred Hutchinson Cancer Research Center, Seattle, Washington ${ }^{7}$ National Institutes of Health Clinical Center, Bethesda, Maryland ${ }^{8}$ Phoenix Children's Center for Cancer and Blood Disorders, Phoenix, Arizona ${ }^{9}$ Children's Center for Cancer and Blood Diseases, Children's Hospital Los Angeles, Los Angeles California ${ }^{10}$ Division of Pediatric Allergy, Immunology, and Bone Marrow Transplantation, University of California San Francisco Benioff Children's Hospital, San Francisco, California ${ }^{11}$ University of Colorado Cancer Center, Aurora, Colorado ${ }^{12}$ Division of Blood and Marrow Transplantation, Center for Cancer and Blood Disorders, Children's National Health System, Washington, District of Columbia ${ }^{13}$ Division of Hematology, Oncology, and Stem Cell Transplantation, Ann \& Robert H. Lurie Children's Hospital of Chicago, Chicago, IL ${ }^{14}$ Pediatric Division of Blood and Marrow Transplantation, Duke School of Medicine, Durham, North Carolina ${ }^{15}$ Oregon Health \& Science University, Knight Cancer Institute, Portland, Oregon ${ }^{16}$ Department of Pediatric Hematology Oncology, Medical College of Wisconsin, Milwaukee, Wisconsin

\section{Abstract}

\begin{abstract}
We analyzed late cardiovascular outcomes of 661 patients who survived at least two years from hematopoietic cell transplantation for childhood hematologic malignancy between 1995 and 2008. Center for International Blood and Marrow Transplant Research data was supplemented with surveys focused on cardiotoxicity and potential risk factors. The median duration of follow-up was 97 months (range 24-230). 4.2\% of survivors experienced at least one of the primary outcomes
\end{abstract}

\footnotetext{
Users may view, print, copy, and download text and data-mine the content in such documents, for the purposes of academic research, subject always to the full Conditions of use: http://www.nature.com/authors/editorial_policies/license.html\#terms

Corresponding Author: Christine N. Duncan, Dana-Farber Cancer Institute, 450 Brookline Ave, Dana 3-126, Boston, MA 02215, P: 617-632-4882 F: 617-632-1990, Christine_duncan@dfci.harvard.edu.

Dr. Pulsipher and Dr. Baker contributed equally.

Conflict of Interest: There are no competing financial interests to report in relations to this work.
} 
including coronary artery disease $(0.2 \%)$, cerebrovascular accident $(0.6 \%)$, cardiomyopathy $(3 \%)$, and cardiac-related death $(0.5 \%)$. Patients who received anthracycline chemotherapy (HR 4.67, p= 0.036 ) or cranial or chest radiation (HR 5.58, $\mathrm{p}<0.0001$; HR 2.18, $\mathrm{p}=0.0087$ ) were at increased risk for developing one of the primary outcomes. Dyslipidemia was diagnosed in $18 \%$ of survivors. Pre-transplant anthracycline (HR 1.74, p < 0.0001) and chest radiation (HR 1.34, p= 0.0371 ) were risk factors for dyslipidemia. Overweight/obese body mass status was present in $63 \%$ of patients at baseline, $65 \%$ at 2 years, and $52 \%$ at most recent evaluation. Diabetes was diagnosed in $7 \%$ of subjects. In conclusion, severe cardiovascular complications were infrequently reported. The incidence of risk factors including obesity and dyslipidemia were significant and will likely increase the risk of cardiovascular disease over time in transplant survivors.

\section{Introduction}

Survivors of allogeneic hematopoietic cell transplantation (HCT) are at risk for cardiovascular (CV) late effects including early cardiac death. ${ }^{1-3}$ Contributing to this risk are genetic predisposition, pretransplant therapeutic exposures, the transplant conditioning regimen, graft-versus-host disease (GVHD) and associated-therapies, post-transplant complications, and life style factors. ${ }^{4-8}$ The majority of the literature regarding late $\mathrm{CV}$ complications of childhood leukemia therapy comes from the study of non-transplant survivors. ${ }^{7,} 9-11$ Far less is known about these late effects following HCT in childhood.

This multicenter study sought to establish the incidence of severe CV related adverse outcomes in a cohort of long-term survivors of childhood transplantation. We examined the incidence of risk factors associated with $\mathrm{CV}$ disease and how they, along with patient and treatment related factors, influenced the development of $\mathrm{CV}$ adverse outcomes.

\section{Materials and Methods}

\section{Study Population}

The study population included patients aged 21 years or less at the time of transplant who survived, relapse-free at least two years following first allogeneic HCT for hematologic malignancy between January 1, 1995 and December 31, 2008. Transplants were performed at twelve Pediatric Blood and Marrow Transplantation Consortium (PBMTC) centers. All patients received a myeloablative conditioning regimen based on the definition published by Bacigalupo, et al. ${ }^{12}$ All stem cell sources and donor types were included except syngeneic twins. Patients who developed one of the primary CV outcomes of interest within the first two years following transplant were excluded from the analysis to distinguish acute toxicity from late effects.

\section{Data Collection}

Data were obtained from the Center for International Blood and Marrow Transplant Research (CIBMTR) database and from pre- and post-HCT supplemental forms. The CIBMTR has a research database with information on more than 425,000 patients. Computerized checks for discrepancies, physicians' review of submitted data and center 
audits ensure data quality. Data are collected before transplant, 100 days and six months after transplant, annually until 6 years, and every other year thereafter, or until death.

Data regarding patient demographics, disease, survival, relapse, graft type, and the presence of GVHD is collected for all patients participating in the CIBMTR repository. A subset of participants are selected for research level data collection including all patients in this study. Centers report the presence of clinically significant organ impairment including the presence of $\mathrm{CV}$ and related late effects.

Data not available in the CIBMTR database were collected on forms focused on pre- and post-transplant exposures. Data obtained from the pre-transplant form included the use of anthracycline chemotherapy in isotoxic doxorubicin equivalents, the use of cranial and/or chest radiation, history of medication treated hypertension, lipid abnormalities, clinically significant cardiomyopathy, coronary artery disease (CAD)/MI, stroke/cerebrovascular accident (CVA), the presence of diabetes treated with medications, and the presence of cardiac structural defect(s). Data from the post-transplant form included the prescription of medications used to treat hypertension, diabetes, or lipid abnormalities; dyslipidemia; the development of new cardiomyopathy, CAD/MI, stroke/CVA; and height and weight at 2 years post-transplant and at most recent follow-up.

Primary Cardiovascular Outcomes-The primary aim of this study was to establish the cumulative incidence of $\mathrm{CV}$ outcomes (CAD/MI, stroke/CVA, cardiomyopathy, and cardiac-related death) in patients who survived disease-free a minimum of two years following allogeneic transplant. CAD/MI or stroke/CVA were recorded if any of the diagnoses were reported by a physician two years or longer after transplant. Clinically significant cardiomyopathy was defined as the presence of decreased ejection or shortening fraction that was determined to be clinically significant by the attending transplant physician and required ongoing treatment or follow-up. There was no specific ejection or shortening fraction required for the diagnosis of cardiomyopathy. It was not determined if the diagnosis was based on routine clinical screening or clinical symptom. Cardiac-related death was reported if the primary cause of death reported was cardiovascular in nature. All reports of cardiac-related deaths were reviewed by two study physicians.

\section{Cardiovascular Risk Factors}

We examined the incidence of risk factors associated with $\mathrm{CV}$ disease including obesity based on body mass index (BMI), diabetes, hypertension, and dyslipidemia. We additionally investigated patient (age, diagnosis, gender, and race) and treatment related factors (preHCT therapy, conditioning regimen, and GVHD) and their effect on CV outcomes.

The BMI was calculated prior to the start of transplant conditioning, 2 years post-HCT, and at most recent follow-up. Normative BMI values are not defined for children less than 2 years old and patients in this age group were excluded from the baseline assessment. BMI status was classified as underweight, normal weight, obese, and overweight based on Centers for Disease Control and Prevention (CDC) definitions. ${ }^{13,}{ }^{14}$ For survivors aged 2 to 20 years, BMI was characterized by calculating an age and sex specific percentile according the 2000 CDC Growth Charts. ${ }^{15}$ In this age group BMI status below $5^{\text {th }}$ percentile was 
classified as underweight, 5\%-84.9\% normal weight, $85 \%-94.9 \%$ overweight, and $95 \%$ and above as obese. For patients older than 20 years a BMI less than 18.5 was classified as underweight, 18.5-24.9 as normal weight, 25-29.9 as overweight, and 30 and greater as obese.

Dyslipidemia was defined as a triglyceride level $>150 \mathrm{mg} / \mathrm{dl}$, high-density lipoprotein (HDL) cholesterol level $<40 \mathrm{mg} / \mathrm{dl}$, and/or low-density lipoprotein (LDL) cholesterol level $>130 \mathrm{mg} / \mathrm{dl}$. A subject was classified as having diabetes if the diagnosis was documented in the patient's medical record and he/she received insulin or oral hypoglycemic medication two years or later after transplant. Hypertension was defined as having elevated blood pressure that was treated with medication.

\section{Statistical Analysis}

Descriptive statistics were used to summarize patient demographic, disease, HCT-related variables, dyslipidemia, and BMI status. The cumulative incidence function was used to estimate the probability of experiencing a primary $\mathrm{CV}$ outcome. No adjustments were made for age at follow-up. Univariate models were developed to assess risk factors for the primary CV outcomes, dyslipidemia, and obesity. Death and relapse were treated as competing risks. Multivariable regression models were not developed due to sample size limitations. All tests were two-sided and $5 \%$ level of significance was used throughout. The same data points were not routinely collected over the entire length of the study at all centers and clinical standards of care evolved over time resulting in missing data. When data were missing, patients were excluded from those analyses affected by the missing data, but included in all other analyses. Analyses were performed using SAS, version 9.3 (SAS Institute, Cary, NC).

\section{Results}

\section{Study Population and Transplant Characteristics}

The final study population included 661 patients. The selection schema is provided in Figure 1. Patient and transplant characteristics are presented in Table 1. The median age at transplantation was 9 years (range <1-21years). The median duration of follow-up was 8 years (range 2-19 years) from transplantation. The CIBMTR completeness index of followup, the ratio of observed versus expected data follow-up, was $96 \%$ at 5 years and $86 \%$ at 10 years, meaning that forms were complete for $96 \%$ of patients at 5 years following transplant. Pre-transplant treatment and CV characteristics are provided in Table 2.

\section{Primary Cardiac Outcomes}

There were 30 diagnoses of one of the primary cardiac outcomes in 28 patients including cardiomyopathy (3\%), stroke/CVA $(0.6 \%)$, cardiac-related death $(0.5 \%)$, and CAD/MI $(0.2 \%)$ (Table 3$)$. The cumulative incidence of the primary outcomes was $1 \%(95 \%$ confidence interval, CI, 1-2\%) at 5-years and 3\% (95\% CI 2-4\%) at 7-years post-transplant. Pre-transplant anthracycline chemotherapy (HR 4.67, $\mathrm{p}=0.0361$ ), cranial radiation (HR $5.58, \mathrm{p}=<0.0001$ ), and chest radiation (HR 2.86, $\mathrm{p}=0.0087$ ) were associated with the development of one or more of the primary outcomes. Patients who received both chest and cranial radiation were at greatest risk for developing one of the primary outcomes compared 
to those who received neither treatment (HR 12.97, $\mathrm{p}<0.001$ ). The doses of anthracycline or radiation were not significantly predictive of the development of one of the primary outcomes Age at transplant, sex, underlying disease, race, donor type, graft source, conditioning regimen, the use of TBI, the diagnosis of GVHD, the diagnosis of dyslipidemia, and BMI were not predictive of the development of one of the primary cardiovascular outcomes. There were 39 patients who had pre-transplant cardiac structural defect, coronary artery disease/myocardial infarction, and/or cardiomyopathy. Of those 39 patients, only 1 (2.5\%) developed the primary outcome following transplant.

\section{Dyslipidemia, Diabetes, and Hypertension}

The cumulative incidence of dyslipidemia diagnosed at any time after transplant was 56\% (95\% CI 52-60) and 63\% (95\% CI 59-67) at 2 years and 5 years post-HCT. The details of cholesterol and triglyceride abnormalities are provided in Table 3. In single predictor, univariable analysis patients who received pre-transplant anthracycline chemotherapy (HR $1.74, \mathrm{p}<0.001)$ or chest radiation $(1.34, \mathrm{p}=0.0371)$ were more likely to be diagnosed with dyslipidemia than those who did not receive those therapies. The risk of dyslipidemia increased $1 \%$ for every $10 \mathrm{mg} / \mathrm{m}^{2}$ increase in the cumulative dose of anthracycline received $(\mathrm{p}=0.0313)$. Increased doses of radiation were not significantly associated with risk of dyslipidemia. Chronic GVHD was a risk factor for the development of dyslipidemia $(\mathrm{HR}=1.45, \mathrm{p}=0.0277)$. Age, sex, underlying diagnosis, race, donor type, graft source, conditioning regimen, the use of TBI, and BMI were not predictive of the development of dyslipidemia. Pre-transplant triglyceride, HDL, and LDL levels were not available for $42 \%$, $77 \%$, and $77 \%$ of patients. Therefore, a potential association between pre- and posttransplant dyslipidemia could not be assessed.

Diabetes requiring medication was diagnosed in $7 \%$ of patients at any time following transplant. Half of the patients received anti-hypertensive medications at some point after HCT inclusive of the first two years after transplant with 9\% still taking them at most recent follow-up.

\section{Body Mass Index}

The BMI status of the population at baseline, two years after transplant, and at most recent evaluation are presented in Table 4. There were more patients with obese status than any other category at each time point assessed. Age, pre-transplant therapy, sex, race, diagnosis, donor source, graft source, conditioning regimen, the use of TBI, presence of GVHD, and baseline BMI were not associated with obesity at 2 years from transplant.

\section{Graft-versus-Host Disease and Survival}

Grade II-IV acute GVHD was diagnosed in $45 \%$ of the population at any time post-HCT and chronic GVHD in $45 \%$ of patients; $11 \%$ diagnosed greater than 2 years from transplant. The overall and progression-free survival at 7 years of patients who were alive, disease-free at least 2 years post-transplant were $94 \%$ and $89 \%$, respectively. The causes of death in the entire study population were GVHD (22 patients, $42 \%$ ), relapse of primary disease (14 patients, 27\%), subsequent malignancy (7 patients, 13\%), infection (3 patients, $6 \%$ ), and other/unknown (6 patients, 12\%). There were three cardiac-related deaths including 2 
cardiac deaths in patients with chronic GVHD and one patient who died of anoxic brain injury following cardio-pulmonary arrest. The patients who died of cardiac related causes included a 14 year old female patient who received an unrelated donor peripheral blood stem cell transplant for AML, a 14 year old male patient who received a matched sibling bone marrow transplant for AML, and a 7 year old boy who received an unrelated donor, bone marrow transplant. The ages provided were those at transplantation. There were two other deaths in the patients who had one of the primary CV outcomes, one of relapse of the primary disease and the other of a subsequent malignancy.

\section{Discussion}

In this multicenter study, we investigated the long-term CV outcomes of 661 patients transplanted for hematologic malignancy during childhood. The largest previously published multicenter studies of late CV toxicity from groups in the United States and the European Group for Blood and Marrow Transplantation included less than 200 per report making this the largest report of these issues following HCT in childhood to date. ${ }^{16,17}$

We report a cumulative incidence of cardiomyopathy, stroke/CVA, CAD/MI, and cardiacrelated death of $1 \%$ at 5 years and $3 \%$ at 7 years post-transplantation. This suggests that the incidence of $\mathrm{CV}$ late effects will increase as the cohort ages, consistent with data from survivors of non-transplant childhood leukemia therapy and adult HCT. ${ }^{1,7,18-20}$ Stroke/ CVA, CAD/MI, and cardiac-related death each occurred in less than $1 \%$ of survivors. The low incidence of these events may be explained by the duration of follow-up and the age of the patients at the time of reporting. Studies of survivors of adult transplantation have shown the development of $\mathrm{CV}$ outcomes at a younger than expected age and that greater toxicity is seen with longer duration of follow-up. ${ }^{3,18,21-23}$ Given the median age of 18.5 years at last follow-up, the survivors in this cohort are young for the development of CV late effects. We hypothesize that the incidence of CV toxicity will increase as the cohort ages and future study will be needed.

Cardiomyopathy was diagnosed in $3 \%$ of patients making it the most common of the primary late effects assessed. This may be explained by the number of patients who received anthracycline chemotherapy and/or radiation therapy prior to transplantation. Anthracycline chemotherapy use is a well-established, dose-dependent risk factor for cardiomyopathy in cancer survivors that is worsened by radiation exposure. ${ }^{10}$ The median cumulative dose of anthracycline received by patients in this cohort, $112 \mathrm{mg} / \mathrm{m}^{2}$, is below that associated with greatest risk of cardiotoxicity. ${ }^{10,11,24,25}$ However, there was a wide range of cumulative dose received with the highest reported dose of $634 \mathrm{mg} / \mathrm{m}^{2}$ and increasing doses of anthracycline were predictive of the development of one of primary outcomes. Based on the small number of events we were unable to determine the additive impact of transplantspecific factors on the development of cardiomyopathy in patients who received anthracycline chemotherapy.

We found that cranial radiation was associated with increased risk of developing one of the primary outcomes. The pathophysiologic mechanism underlying this risk is unclear. A potential explanation relates radiation-mediated hypothalamic-pituitary dysfunction leading 
to growth hormone deficiency and decreased synthesis of insulin-like growth factor-1 (IGF-1) ${ }^{26}$ Deficiency of growth hormone and/or IGF-1 have been linked to myocardial hypokinesis, altered cardiac growth, and abnormal response to exercise. ${ }^{26-29} \mathrm{~A}$ single center study compared the cardiac structure and function of 13 survivors of childhood cancer therapy who received cranial radiation therapy without systemic chemotherapy to their healthy siblings. ${ }^{26}$ They found that the childhood cancer survivors who received cranial radiation therapy had lower IGF-1 levels, smaller cardiac volumes and decreased left ventricular systolic and diastolic function compared to their siblings. A separate study of childhood cancer survivors reported that treatment with cranial radiation and anthracycline chemotherapy were associated with decreases in left ventricular mass and dimension greater than those who received anthracycline chemotherapy without radiation. ${ }^{30}$

We did not identify associations of transplant specific factors with the development of one of the primary cardiovascular outcomes. The only transplant-related factor associated with any study outcome was that of chronic GVHD with dyslipidemia. This result may have been confounded by the use of medications used to treat GVHD that can cause lipid abnormalities such as corticosteroid and sirolimus. The lack of association of TBI with the development of one of the primary $\mathrm{CV}$ outcomes, dyslipidemia, or obesity was unexpected and differs from prior reports that identified it as an independent risk factor for late $\mathrm{CV}$ toxicity. ${ }^{31,}{ }^{32} \mathrm{~A}$ potential explanation is that survivors who received non-TBI based conditioning may have had additional factors that increased their risk for $\mathrm{CV}$ outcomes making it difficult to distinguish the impact of TBI. Another potential explanation is that the conditioning agents used instead of TBI may have late deleterious cardiovascular effects similar to those seen following radiation therapy.

Cholesterol abnormalities and dyslipidemia are risk factors for childhood CV illness that influence the development of disease in adulthood. ${ }^{33}$ Data from the 2011-2014 National Health and Nutrition Examination Surveys (NHANES) showed that 21\% of children aged 619 years had at least one abnormal cholesterol measure with low HDL and high non-HDL reported in $13.4 \%$ and $8.4 \%$ of those tested. ${ }^{34}$ The prevalence increased with BMI status and older age. ${ }^{34}$ We report low HDL and high LDL cholesterol measures in $15 \%$ and $10 \%$ of patients tested, comparable to those described in the NHANES of otherwise healthy children. ${ }^{35}$ The American Academy of Pediatrics (AAP) and expert panel recommendations advise universal lipid screening of all 9-11 year old children with additional screening of younger children and adolescents based on individual $\mathrm{CV}$ risk factors and family history. 36, 37 Due to the large amount of missing cholesterol data we are unable provide data derived screening guidelines for transplant survivors. However, we suggest that at minimum patients should have the routine surveillance recommended by expert panel and the AAP. ${ }^{34,36,3735}$ Furthermore, we advocate for heightened surveillance in survivors with additional risk factors including history of GVHD, obesity and older age. The large number of patients with missing lipid measurements in our study suggests that regular monitoring may not be performed at all transplant centers. If dyslipidemia screening is not routinely performed by the HCT center, then survivors should be counselled to have testing completed by another medical professional. 
Childhood obesity is a significant problem in the general population and pediatric cancer survivors. The negative impact of childhood obesity on factors associated with CV health is well-documented and may influence the development of hypertension, cholesterol abnormalities, diabetes, and insulin insensitivity in adulthood. ${ }^{38,39}$ Reports of obese and overweight/obese status in the general population of 2-19 year old children are $16.9 \%$ and $31.7 \% .^{40}$ There is a range of obesity estimates in adult survivors of childhood non-transplant leukemia therapy with reported rates of $16-43 \% .{ }^{41-45}$ This study found rates of overweight/ obese BMI status of $63 \%$ and $52 \%$ of those with available data at baseline and most recent follow-up respectively, exceeding those reported in the general population and survivors of non-HCT childhood cancer therapy. However, $35 \%$ of patients had missing BMI data at baseline and it is possible that this affected the reported rates of overweight/obese status. The high rate of obese/overweight BMI status at baseline may have been in part due to recent pretransplant leukemia directed therapies, including corticosteroid. These results support routine assessment for and counseling about optimal weight and body mass in transplant survivors. Interventions to effectively decrease the risk of obesity are needed.

There are limitations to this study. There was lack of uniformity in clinical practice between centers and standards of care changed during the 13-year study window resulting in missing data that may have affected the reported outcomes with a bias likely in the direction of underreporting. Precise start dates for medications were not reliably recorded in the medical record, which made it impossible to determine the date of diagnosis for conditions such as diabetes that relied on medication use. In these cases, we were unable to discern acute toxicity from true late effect. Patients with diabetes/hyperglycemia and/or hypertension treated with nonpharmaceutical, lifestyle modification were not reported as having either late effect. It is possible that this lead to an underestimation of the true incidence of these long-term toxicities. Additionally, we were unable to assess potential predictive factors, such as genetics and lifestyle behaviors due to the retrospective nature of the study and we were unable to perform multivariate analysis due to the small number of primary events. We were unable to investigate the incidence or impact of body composition alteration, such as sarcopenic obesity, on CV health as these data were not routinely collected by the participating centers. Finally, while the patients in this cohort are representative of those transplanted for hematologic malignancy, the results cannot be extrapolated to those transplanted for other indications. Future study of the CV late effects in survivors of transplant for non-malignant conditions is needed.

In summary, this is the largest study of CV late effects in survivors of childhood allogeneic HCT to date. We have shown that while the primary outcomes of interest were infrequently reported, related late effects and $\mathrm{CV}$ risk factors are common in survivors of HCT for childhood hematologic malignancy. The cumulative incidence of these events is expected to increase as the cohort ages. Prospective, long-term studies are needed to further elucidate the roles of genetics, lifestyle, and the transplant process in the development of cardiotoxicity, along with testing interventions to decrease the high incidence of cardiac risk factors described in this study. 


\title{
Supplementary Material
}

Refer to Web version on PubMed Central for supplementary material.

\section{Acknowledgments}

This study was sponsored by the Jeff Gordon Children's Foundation and the Pediatric Blood and Marrow Transplant Consortium

\author{
CIBMTR Support List
}

The CIBMTR is supported primarily by Public Health Service Grant/Cooperative Agreement 5U24-CA076518 from the National Cancer Institute (NCI), the National Heart, Lung and Blood Institute (NHLBI) and the National Institute of Allergy and Infectious Diseases (NIAID); a Grant/Cooperative Agreement 5U10HL069294 from NHLBI and NCI; a contract HHSH250201200016C with Health Resources and Services Administration (HRSA/ DHHS); two Grants N00014-15-1-0848 and N00014-16-1-2020 from the Office of Naval Research; and grants from *Actinium Pharmaceuticals, Inc.; Alexion; *Amgen, Inc.; Anonymous donation to the Medical College of Wisconsin; Astellas Pharma US; AstraZeneca; Atara Biotherapeutics, Inc.; Be the Match Foundation; *Bluebird Bio, Inc.; *Bristol Myers Squibb Oncology; *Celgene Corporation; Cellular Dynamics International, Inc.; Cerus Corporation; *Chimerix, Inc.; Fred Hutchinson Cancer Research Center; Gamida Cell Ltd.; Genentech, Inc.; Genzyme Corporation; Gilead Sciences, Inc.; Health Research, Inc. Roswell Park Cancer Institute; HistoGenetics, Inc.; Incyte Corporation; Janssen Scientific Affairs, LLC; *Jazz Pharmaceuticals, Inc.; Jeff Gordon Children's Foundation; The Leukemia \& Lymphoma Society; Medac, GmbH; MedImmune; The Medical College of Wisconsin; *Merck \& Co, Inc.; *Mesoblast; MesoScale Diagnostics, Inc.; *Miltenyi Biotec, Inc.; National Marrow Donor Program; Neovii Biotech NA, Inc.; Novartis Pharmaceuticals Corporation; Onyx Pharmaceuticals; Optum Healthcare Solutions, Inc.; Otsuka America Pharmaceutical, Inc.; Otsuka Pharmaceutical Co, Ltd. - Japan; PCORI; Perkin Elmer, Inc.; Pfizer, Inc; *Sanofi US; *Seattle Genetics; *Spectrum Pharmaceuticals, Inc.; St. Baldrick's Foundation; *Sunesis Pharmaceuticals, Inc.; Swedish Orphan Biovitrum, Inc.; Takeda Oncology; Telomere Diagnostics, Inc.; University of Minnesota; and *Wellpoint, Inc. The views expressed in this article do not reflect the official policy or position of the National Institute of Health, the Department of the Navy, the Department of Defense, Health Resources and Services Administration (HRSA) or any other agency of the U.S. Government.

*Corporate Members

The study was designed by CND, RB, MAP, KSB, BS, NM. Data analysis was performed by JH and RB and data interpretation by CND, RB, JH, BES, MAP, KSB. The manuscript was written by CND, RB, JH, BES, MAP, KSB. $\mathrm{CND}, \mathrm{KB}, \mathrm{AD}, \mathrm{CCD}, \mathrm{RG}, \mathrm{DAJ}, \mathrm{MK}, \mathrm{PLM}, \mathrm{ERN}, \mathrm{JT}, \mathrm{MAP}, \mathrm{KSB}$ participated in data collection and review. All of the authors participated in reviewing and approving the protocol and manuscript

\section{References}

1. Armenian SH, Chow EJ. Cardiovascular disease in survivors of hematopoietic cell transplantation. Cancer. 2014; 120(4):469-479. DOI: 10.1002/cncr.28444 [PubMed: 24166350]

2. Baker KS, Chow E, Steinberger J. Metabolic syndrome and cardiovascular risk in survivors after hematopoietic cell transplantation. Bone marrow transplantation. 2012; 47(5):619-625. e-pub ahead of print 2011/06/07. DOI: 10.1038/bmt.2011.118 [PubMed: 21643022]

3. Chow EJ, Wong K, Lee SJ, Cushing-Haugen KL, Flowers ME, Friedman DL, et al. Late cardiovascular complications after hematopoietic cell transplantation. Biology of blood and marrow transplantation : journal of the American Society for Blood and Marrow Transplantation. 2014; 20(6):794-800. DOI: 10.1016/j.bbmt.2014.02.012

4. Baker KS, Bhatia S, Bunin N, Nieder M, Dvorak CC, Sung L, et al. NCI, NHLBI first international consensus conference on late effects after pediatric hematopoietic cell transplantation: state of the science, future directions. Biology of blood and marrow transplantation : journal of the American Society for Blood and Marrow Transplantation. 2011; 17(10):1424-1427. e-pub ahead of print 2011/07/05. DOI: 10.1016/j.bbmt.2011.06.007

5. Dvorak CC, Gracia CR, Sanders JE, Cheng EY, Baker KS, Pulsipher MA, et al. NCI, NHLBI/ PBMTC first international conference on late effects after pediatric hematopoietic cell transplantation: endocrine challenges-thyroid dysfunction, growth impairment, bone health, \& reproductive risks. Biology of blood and marrow transplantation : journal of the American Society 
for Blood and Marrow Transplantation. 2011; 17(12):1725-1738. e-pub ahead of print 2011/10/19. DOI: 10.1016/j.bbmt.2011.10.006

6. Landier W, Armenian S, Bhatia S. Late effects of childhood cancer and its treatment. Pediatric clinics of North America. 2015; 62(1):275-300. DOI: 10.1016/j.pcl.2014.09.017 [PubMed: 25435123]

7. Nieder ML, McDonald GB, Kida A, Hingorani S, Armenian SH, Cooke KR, et al. National Cancer Institute-National Heart, Lung and Blood Institute/pediatric Blood and Marrow Transplant Consortium First International Consensus Conference on late effects after pediatric hematopoietic cell transplantation: long-term organ damage and dysfunction. Biol Blood Marrow Transplant. 2011; 17(11):1573-1584. e-pub ahead of print 2011/10/04. DOI: 10.1016/j.bbmt.2011.09.013 [PubMed: 21963877]

8. Chow EJ, Baker KS, Lee SJ, Flowers ME, Cushing-Haugen KL, Inamoto Y, et al. Influence of conventional cardiovascular risk factors and lifestyle characteristics on cardiovascular disease after hematopoietic cell transplantation. Journal of clinical oncology : official journal of the American Society of Clinical Oncology. 2014; 32(3):191-198. DOI: 10.1200/JCO.2013.52.6582 [PubMed: 24297944]

9. Akam-Venkata J, Franco VI, Lipshultz SE. Late Cardiotoxicity: Issues for Childhood Cancer Survivors. Curr Treat Options Cardiovasc Med. 2016; 18(7):47.doi: 10.1007/s11936-016-0466-6 [PubMed: 27230282]

10. Lipshultz SE, Colan SD, Gelber RD, Perez-Atayde AR, Sallan SE, Sanders SP. Late cardiac effects of doxorubicin therapy for acute lymphoblastic leukemia in childhood. The New England journal of medicine. 1991; 324(12):808-815. DOI: 10.1056/NEJM199103213241205 [PubMed: 1997853]

11. Lipshultz SE, Lipsitz SR, Sallan SE, Dalton VM, Mone SM, Gelber RD, et al. Chronic progressive cardiac dysfunction years after doxorubicin therapy for childhood acute lymphoblastic leukemia. J Clin Oncol. 2005; 23(12):2629-2636. DOI: 10.1200/JCO.2005.12.121 [PubMed: 15837978]

12. Bacigalupo A, Ballen K, Rizzo D, Giralt S, Lazarus H, Ho V, et al. Defining the intensity of conditioning regimens: working definitions. Biology of blood and marrow transplantation : journal of the American Society for Blood and Marrow Transplantation. 2009; 15(12):1628-1633. DOI: 10.1016/j.bbmt.2009.07.004

13. Division of Nutrition PA, and Obesity, National Center for Chronic Disease Prevention and Health Promotion. Defining Adult Overweight and Obesity. 2016. http://www.cdc.gov/obesity/adult/ defining.html

14. Division of Nutrition PA, and Obesity, National Center for Chronic Disease Prevention and Health Promotion. Defining Childhood Obesity. 2015. http://www.cdc.gov/obesity/childhood/ defining.html

15. Centers for Disease Control and Prevention NCfHS. Individual Growth Charts. 2009. http:// www.cdc.gov/growthcharts/charts.htm

16. Uderzo C, Pillon M, Corti P, Tridello G, Tana F, Zintl F, et al. Impact of cumulative anthracycline dose, preparative regimen and chronic graft-versus-host disease on pulmonary and cardiac function in children 5 years after allogeneic hematopoietic stem cell transplantation: a prospective evaluation on behalf of the EBMT Pediatric Diseases and Late Effects Working Parties. Bone marrow transplantation. 2007; 39(11):667-675. DOI: 10.1038/sj.bmt.1705652 [PubMed: 17401396]

17. Slater ME, Steinberger J, Ross JA, Kelly AS, Chow EJ, Koves IH, et al. Physical Activity, Fitness, and Cardiometabolic Risk Factors in Adult Survivors of Childhood Cancer with a History of Hematopoietic Cell Transplantation. Biology of blood and marrow transplantation : journal of the American Society for Blood and Marrow Transplantation. 2015; 21(7):1278-1283. DOI: 10.1016/ j.bbmt.2015.04.007

18. Tichelli A, Bucher C, Rovo A, Stussi G, Stern M, Paulussen M, et al. Premature cardiovascular disease after allogeneic hematopoietic stem-cell transplantation. Blood. 2007; 110(9):3463-3471. DOI: 10.1182/blood-2006-10-054080 [PubMed: 17664354]

19. Simbre VC, Duffy SA, Dadlani GH, Miller TL, Lipshultz SE. Cardiotoxicity of cancer chemotherapy: implications for children. Paediatric drugs. 2005; 7(3):187-202. [PubMed: 15977964] 
20. Mulrooney DA, Armstrong GT, Huang S, Ness KK, Ehrhardt MJ, Joshi VM, et al. Cardiac Outcomes in Adult Survivors of Childhood Cancer Exposed to Cardiotoxic Therapy: A Crosssectional Study. Annals of internal medicine. 2016; 164(2):93-101. DOI: 10.7326/M15-0424 [PubMed: 26747086]

21. Armenian SH, Sun CL, Mills G, Teh JB, Francisco L, Durand JB, et al. Predictors of late cardiovascular complications in survivors of hematopoietic cell transplantation. Biology of blood and marrow transplantation : journal of the American Society for Blood and Marrow Transplantation. 2010; 16(8):1138-1144. DOI: 10.1016/j.bbmt.2010.02.021

22. Baker KS, Ness KK, Steinberger J, Carter A, Francisco L, Burns LJ, et al. Diabetes, hypertension, and cardiovascular events in survivors of hematopoietic cell transplantation: a report from the bone marrow transplantation survivor study. Blood. 2007; 109(4):1765-1772. DOI: 10.1182/ blood-2006-05-022335 [PubMed: 17047152]

23. Tichelli A, Bhatia S, Socie G. Cardiac and cardiovascular consequences after haematopoietic stem cell transplantation. British journal of haematology. 2008; 142(1):11-26. DOI: 10.1111/j. 1365-2141.2008.07165.x [PubMed: 18430191]

24. Nysom K, Holm K, Lipsitz SR, Mone SM, Colan SD, Orav EJ, et al. Relationship between cumulative anthracycline dose and late cardiotoxicity in childhood acute lymphoblastic leukemia. Journal of clinical oncology : official journal of the American Society of Clinical Oncology. 1998; 16(2):545-550. [PubMed: 9469339]

25. Kremer LC, van Dalen EC, Offringa M, Ottenkamp J, Voute PA. Anthracycline-induced clinical heart failure in a cohort of 607 children: long-term follow-up study. Journal of clinical oncology : official journal of the American Society of Clinical Oncology. 2001; 19(1):191-196. [PubMed: 11134212]

26. Hummel YM, Hooimeijer HL, Zwart N, Tissing WJ, Gietema JA, Voors AA, et al. Long-term cardiac abnormalities after cranial radiotherapy in childhood cancer survivors. Acta oncologica. 2015; 54(4):515-521. DOI: 10.3109/0284186X.2014.969845 [PubMed: 25333757]

27. Thomas JD, Dattani A, Zemrak F, Burchell T, Akker SA, Gurnell M, et al. Characterisation of myocardial structure and function in adult-onset growth hormone deficiency using cardiac magnetic resonance. Endocrine. 2016; doi: 10.1007/s12020-016-1067-6

28. Widdowson WM, Gibney J. The effect of growth hormone replacement on exercise capacity in patients with GH deficiency: a metaanalysis. The Journal of clinical endocrinology and metabolism. 2008; 93(11):4413-4417. DOI: 10.1210/jc.2008-1239 [PubMed: 18697875]

29. Salerno M, Esposito V, Spinelli L, Di Somma C, Farina V, Muzzica S, et al. Left ventricular mass and function in children with GH deficiency before and during 12 months GH replacement therapy. Clinical endocrinology. 2004; 60(5):630-636. DOI: 10.1111/j.1365-2265.2004.02026.x [PubMed: 15104568]

30. Landy DC, Miller TL, Lipsitz SR, Lopez-Mitnik G, Hinkle AS, Constine LS, et al. Cranial irradiation as an additional risk factor for anthracycline cardiotoxicity in childhood cancer survivors: an analysis from the cardiac risk factors in childhood cancer survivors study. Pediatric cardiology. 2013; 34(4):826-834. DOI: 10.1007/s00246-012-0539-6 [PubMed: 23080542]

31. Meacham LR, Chow EJ, Ness KK, Kamdar KY, Chen Y, Yasui Y, et al. Cardiovascular risk factors in adult survivors of pediatric cancer--a report from the childhood cancer survivor study. Cancer epidemiology, biomarkers \& prevention : a publication of the American Association for Cancer Research, cosponsored by the American Society of Preventive Oncology. 2010; 19(1):170-181. DOI: 10.1158/1055-9965.EPI-09-0555

32. Chow EJ, Simmons JH, Roth CL, Baker KS, Hoffmeister PA, Sanders JE, et al. Increased cardiometabolic traits in pediatric survivors of acute lymphoblastic leukemia treated with total body irradiation. Biology of blood and marrow transplantation : journal of the American Society for Blood and Marrow Transplantation. 2010; 16(12):1674-1681. DOI: 10.1016/j.bbmt. 2010.05.016

33. Webber LS, Srinivasan SR, Wattigney WA, Berenson GS. Tracking of serum lipids and lipoproteins from childhood to adulthood. The Bogalusa Heart Study. American journal of epidemiology. 1991; 133(9):884-899. [PubMed: 2028978]

34. Nguyen D. Abnormal cholesterol among children and adolescents in the United States, 2011-2014. National Center for Health Statistics; Hyattsville, MD: 2015. 
35. Nguyen DTKB, Carroll MD. Abnormal Cholesterol Among Children and Adolescents in the United States, 2011-2014. National Center for Health Statistics; Hyattsville, MD: 2015.

36. Expert Panel on Integrated Guidelines for Cardiovascular H; Risk Reduction in C; Adolescents, National Heart L, Blood I. Expert panel on integrated guidelines for cardiovascular health and risk reduction in children and adolescents: summary report. Pediatrics. 2011; 128(Suppl 5):S213-256. DOI: 10.1542/peds.2009-2107C [PubMed: 22084329]

37. 2015 Recommendations for Preventive Pediatric Health Care Committee on Practice and Ambulatory Medicine and Bright Futures Periodicity Schedule Workgroup. Pediatrics. 2015; doi: 10.1542/peds.2015-2009

38. Freedman DS, Mei Z, Srinivasan SR, Berenson GS, Dietz WH. Cardiovascular risk factors and excess adiposity among overweight children and adolescents: the Bogalusa Heart Study. The Journal of pediatrics. 2007; 150(1):12-17. e12. DOI: 10.1016/j.jpeds.2006.08.042 [PubMed: 17188605]

39. Whitlock EP, Williams SB, Gold R, Smith PR, Shipman SA. Screening and interventions for childhood overweight: a summary of evidence for the US Preventive Services Task Force. Pediatrics. 2005; 116(1):e125-144. DOI: 10.1542/peds.2005-0242 [PubMed: 15995013]

40. Ogden CL, Carroll MD, Kit BK, Flegal KM. Prevalence of childhood and adult obesity in the United States, 2011-2012. Jama. 2014; 311(8):806-814. DOI: 10.1001/jama.2014.732 [PubMed: 24570244]

41. Gibson TM, Ehrhardt MJ, Ness KK. Obesity and Metabolic Syndrome Among Adult Survivors of Childhood Leukemia. Current treatment options in oncology. 2016; 17(4):17.doi: 10.1007/ s11864-016-0393-5 [PubMed: 26951206]

42. Rogers PC, Meacham LR, Oeffinger KC, Henry DW, Lange BJ. Obesity in pediatric oncology. Pediatric blood \& cancer. 2005; 45(7):881-891. DOI: 10.1002/pbc.20451 [PubMed: 16035086]

43. Oeffinger KC, Mertens AC, Sklar CA, Yasui Y, Fears T, Stovall M, et al. Obesity in adult survivors of childhood acute lymphoblastic leukemia: a report from the Childhood Cancer Survivor Study. Journal of clinical oncology : official journal of the American Society of Clinical Oncology. 2003; 21(7):1359-1365. [PubMed: 12663727]

44. Garmey EG, Liu Q, Sklar CA, Meacham LR, Mertens AC, Stovall MA, et al. Longitudinal changes in obesity and body mass index among adult survivors of childhood acute lymphoblastic leukemia: a report from the Childhood Cancer Survivor Study. Journal of clinical oncology : official journal of the American Society of Clinical Oncology. 2008; 26(28):4639-4645. DOI: 10.1200/JCO. 2008.16.3527 [PubMed: 18824710]

45. Oeffinger KC, Buchanan GR, Eshelman DA, Denke MA, Andrews TC, Germak JA, et al. Cardiovascular risk factors in young adult survivors of childhood acute lymphoblastic leukemia. Journal of pediatric hematology/oncology. 2001; 23(7):424-430. [PubMed: 11878576] 
Transplanted for AML, ALL, CML, MDS, or JMML

$\mathrm{N}=2968$

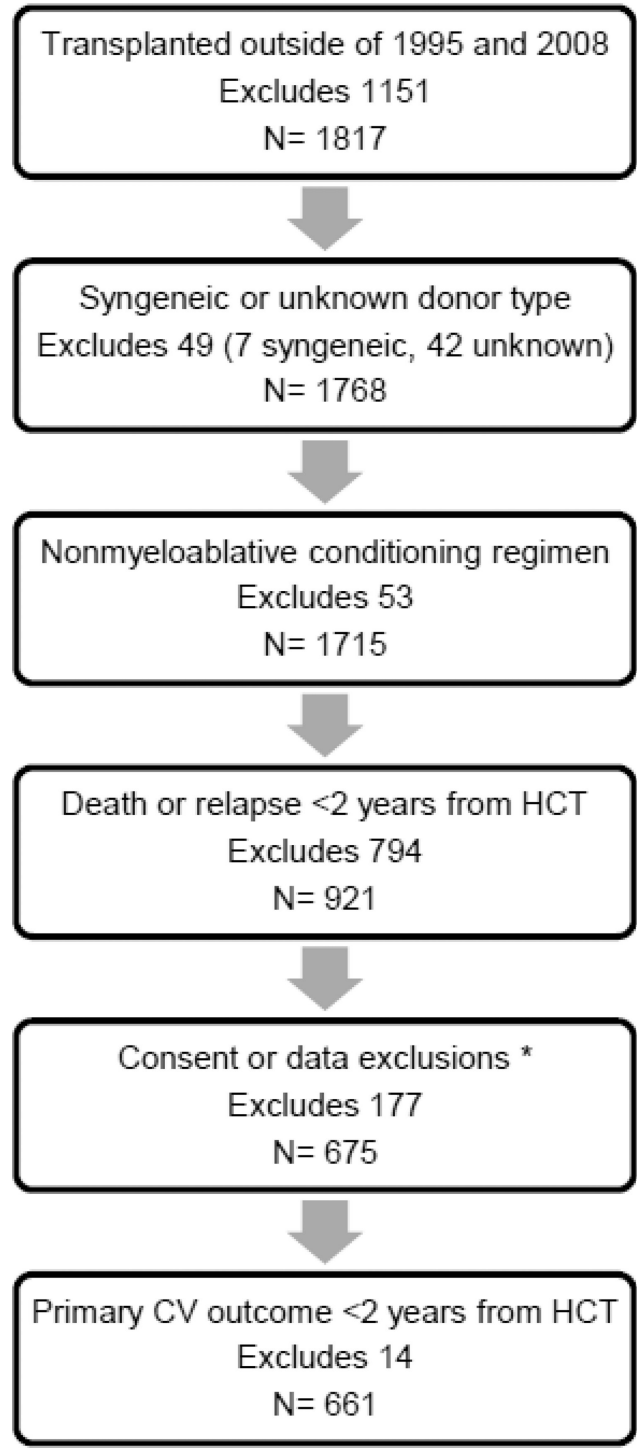

Figure 1.

Study population schema

* Includes subjects who did not consent to CIBMTR research; had missing research data or information about diagnosis or outcome at 2 years; subjects who had a second transplant in the 2 years after first HCT; data no longer required by CIBMTR, and study forms incomplete by study closing date. 


\section{Table 1}

Characteristics of the study population

\begin{tabular}{|c|c|}
\hline Variable & $\mathbf{N}(\%)$ \\
\hline \multicolumn{2}{|l|}{ Year of transplant } \\
\hline 1995-1999 & $161(24)$ \\
\hline 2000-2004 & $229(35)$ \\
\hline $2005-2008$ & $271(41)$ \\
\hline \multicolumn{2}{|l|}{ Age at HCT,years $(\mathrm{N}=661)$} \\
\hline Median, range & $8.8(0.3-20.9)$ \\
\hline $0-4$ & $173(26)$ \\
\hline $5-9$ & $200(30)$ \\
\hline $10-14$ & $164(25)$ \\
\hline $15-21$ & $124(19)$ \\
\hline \multicolumn{2}{|l|}{ Age at end of study follow-up, years } \\
\hline Median, range & $18.5(3.0-38.0)$ \\
\hline $0-9$ & $73(11)$ \\
\hline $10-19$ & $326(49)$ \\
\hline $20-29$ & $236(36)$ \\
\hline $30-38$ & $26(4 \%)$ \\
\hline Male/Female & $367(56) / 294(44)$ \\
\hline \multicolumn{2}{|l|}{ Race } \\
\hline Caucasian & $509(82)^{*}$ \\
\hline African American & $46(7)^{*}$ \\
\hline Hispanic & $40(6)^{*}$ \\
\hline Asian & $25(4)^{*}$ \\
\hline Other & $5(1)^{*}$ \\
\hline Unknown & $36(5)$ \\
\hline \multicolumn{2}{|l|}{ Underlying disease } \\
\hline ALL & $326(49)$ \\
\hline AML & $203(31)$ \\
\hline MDS & $65(10)$ \\
\hline CML & $55(8)$ \\
\hline JMML & $12(2)$ \\
\hline \multicolumn{2}{|l|}{ Donor } \\
\hline Matched, related donor & $236(36)$ \\
\hline Matched, unrelated donor & $169(25)$ \\
\hline Mismatched, unrelated donor & $236(36)$ \\
\hline Unknown matching, unrelated donor & $20(3)$ \\
\hline
\end{tabular}

Bone Marrow Transplant. Author manuscript; available in PMC 2018 September 27. 


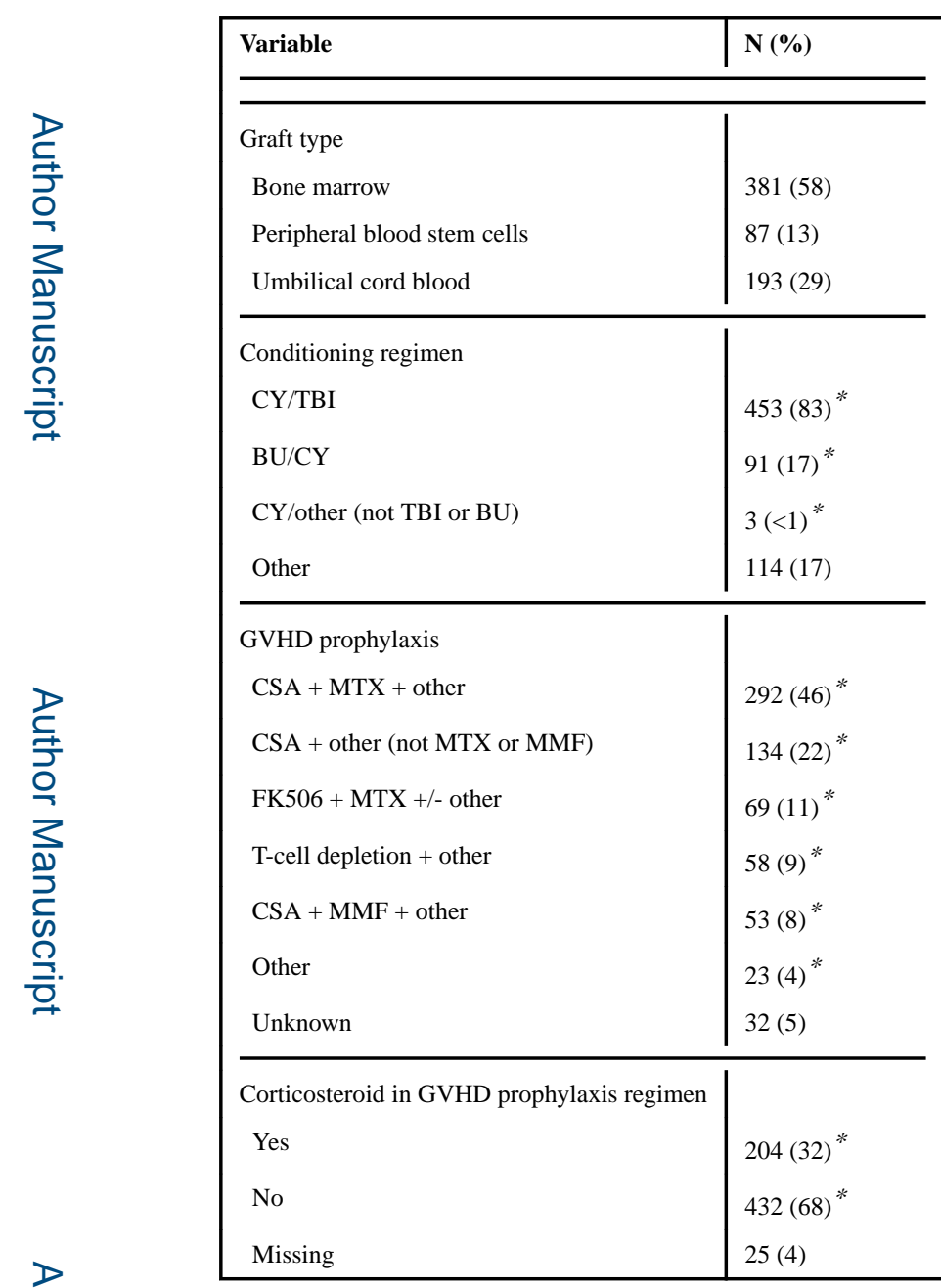

$\mathrm{CY}=$ cyclophosphamide, $\mathrm{BU}=$ busulfan, $\mathrm{TBI}=$ total body irradiation, $\mathrm{CSA}=$ cyclosporine, $\mathrm{MTX}=$ methotrexate *

Percentage reported based on number of subjects with available data, patients with unknown data excluded. 


\section{Table 2}

Pretransplant treatment and CV characteristics

\begin{tabular}{|c|c|}
\hline Variable & $\mathbf{N}(\%){ }^{*}$ \\
\hline \multicolumn{2}{|l|}{ PreHCT anthracycline } \\
\hline Yes & $482(73)$ \\
\hline No & $175(27)$ \\
\hline Unknown & $4(<1)$ \\
\hline Median anthracycline dose, $\mathrm{mg} / \mathrm{m} 2$ (range) & $112(7-634)$ \\
\hline \multicolumn{2}{|l|}{ PreHCT cranial radiation } \\
\hline Yes & $118(19)$ \\
\hline No & $504(81)$ \\
\hline Unknown & $39(6)$ \\
\hline Median cranial radiation dose, cGy (range) & $1200(12-5040)$ \\
\hline \multicolumn{2}{|l|}{ PreHCT chest radiation } \\
\hline Yes & $86(14)$ \\
\hline No & $540(86)$ \\
\hline Unknown & $35(5)$ \\
\hline Median chest radiation dose, cGy (range) & $700(10-5040)$ \\
\hline \multicolumn{2}{|l|}{ Hypertension } \\
\hline Yes & $25(4)$ \\
\hline No & $576(96)$ \\
\hline Unknown & $60(9)$ \\
\hline \multicolumn{2}{|l|}{ Diabetes or hyperglycemia } \\
\hline Yes & $14(2)$ \\
\hline No & $604(98)$ \\
\hline Unknown & $43(7)$ \\
\hline \multicolumn{2}{|l|}{ Triglycerides $>150 \mathrm{mg} / \mathrm{dl}$} \\
\hline Yes & $91(24)$ \\
\hline No & $292(76)$ \\
\hline Missing & $278(42)$ \\
\hline \multicolumn{2}{|l|}{ HDL cholesterol $<40 \mathrm{mg} / \mathrm{dl}$} \\
\hline Yes & $4(3)$ \\
\hline No & $151(97)$ \\
\hline Missing & $506(77)$ \\
\hline \multicolumn{2}{|l|}{ LDL cholesterol $>130 \mathrm{mg} / \mathrm{dl}$} \\
\hline Yes & $3(2)$ \\
\hline No & $151(98)$ \\
\hline Missing & $507(77)$ \\
\hline
\end{tabular}

Bone Marrow Transplant. Author manuscript; available in PMC 2018 September 27. 


\begin{tabular}{|l|l|}
\hline Variable & $\mathbf{N}(\boldsymbol{\%})^{*}$ \\
\hline Cardiomyopathy & $10(2)$ \\
Yes & $629(98)$ \\
No & $22(3)$ \\
Not assessed & \\
\hline Cardiac structural defect at diagnosis & $29(4)$ \\
Yes & $628(96)$ \\
No & $4(<1)$ \\
Missing & $1(<1)$ \\
\hline CAD/myocardial infarction & $632(99)$ \\
Yes & $28(4)$ \\
No & Missing \\
\hline
\end{tabular}

$\mathrm{HDL}=$ high-density lipoprotein, $\mathrm{LDL}=$ low-density lipoprotein, $\mathrm{CAD}=$ coronary artery disease

* Percentages reported for the categories "unknown" and "missing" reflect the entire population, n=661. The percentages reported for all other variables are based on the available data and excludes the number of subjects with missing data. 


\section{Table 3}

Cardiovascular and metabolic events.

\begin{tabular}{|c|c|}
\hline Variable & $\mathbf{N}(\%)^{\delta}$ \\
\hline $\mathrm{CAD} / \mathrm{MI}$ & $1(0.2)$ \\
\hline Stroke/CVA & $4(0.6)$ \\
\hline Cardiomyopathy & $22(3)$ \\
\hline Cardiac-related death & $3(0.5)$ \\
\hline \multicolumn{2}{|l|}{ Multiple events $*$} \\
\hline Cardiomyopathy + cardiac-related death & $1(0.2)$ \\
\hline Cardiomyopathy + stroke/CVA & $1(0.2)$ \\
\hline \multicolumn{2}{|l|}{ Dyslipidemia $\varphi$} \\
\hline Yes & $98(18)$ \\
\hline No & $453(82)$ \\
\hline Unknown & $110(17)$ \\
\hline \multicolumn{2}{|l|}{ Triglyceride $>150 \mathrm{mg} / \mathrm{dl}$} \\
\hline Yes & $72(14)$ \\
\hline No & $425(86)$ \\
\hline Unknown & $164(25)$ \\
\hline \multicolumn{2}{|l|}{ HDL cholesterol $<40 \mathrm{mg} / \mathrm{dl}$} \\
\hline Yes & $98(30)$ \\
\hline No & $231(70)$ \\
\hline Unknown & $332(50)$ \\
\hline \multicolumn{2}{|l|}{ LDL cholesterol $>130 \mathrm{mg} / \mathrm{dl}$} \\
\hline Yes & $63(20)$ \\
\hline No & $253(80)$ \\
\hline Unknown & $345(52)$ \\
\hline \multicolumn{2}{|l|}{ Diabetes or hyperglycemia } \\
\hline Yes & $47(8)$ \\
\hline No & $560(92)$ \\
\hline Unknown & $54(8)$ \\
\hline
\end{tabular}

$\mathrm{CAD}=$ coronary artery disease $\mathrm{MI}=$ myocardial infarction $; \mathrm{CVA}=$ cerebrovascular accident

The individual events included in the category multiple events were counted separately in the rows above (e.g. 22 total patients had cardiomyopathy; 20 had only cardiomyopathy, 2 had cardiomyopathy and another event)

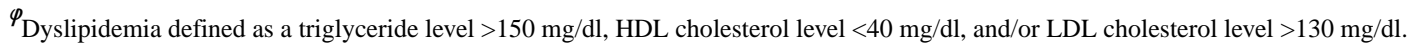

$\delta_{\text {Perce }}$ on the available data and excludes the number of subjects with missing/unknown data.

Bone Marrow Transplant. Author manuscript; available in PMC 2018 September 27. 
Table 4

BMI status at baseline, 2 years post-transplant, and most recent follow-up

\begin{tabular}{|c|c|c|c|}
\hline & Baseline, $\mathbf{N}(\boldsymbol{\%}) \boldsymbol{\varphi}^{*}$ & Two Years, $\mathbf{N}(\boldsymbol{\%}) \boldsymbol{\varphi}$ & $\begin{array}{c}\text { Most Recent } \\
\text { Follow-up, } \mathbf{N}(\boldsymbol{\%}) \boldsymbol{\varphi}\end{array}$ \\
\hline Underweight & $10(3)$ & $15(3)$ & $54(9)$ \\
\hline Normal weight & $133(34)$ & $159(32)$ & $242(39)$ \\
\hline Overweight & $31(8)$ & $51(10)$ & $75(12)$ \\
\hline Obese & $215(55)$ & $276(55)$ & $251(40)$ \\
\hline Missing Data & $213(35)$ & $160(24)$ & $39(6)$ \\
\hline
\end{tabular}

59 subjects $(9 \%)$ were excluded from the baseline assessment due to age less than 2 years.

$\varphi$ Percentages reported for the category "Missing Data" reflect the entire population. The percentages reported for all other variables are based on the available data and excludes the number of subjects with missing data. 